\title{
Irritable Bowel Syndrome-Like Symptoms in Ulcerative Colitis Patients in Clinical Remission: Association with Residual Colonic Inflammation
}

\author{
Shunji Ishihara ${ }^{a, b}$ Kousaku Kawashima ${ }^{a, b} \quad$ Nobuhiko Fukubab \\ Yasumasa Tada $^{\mathrm{b}}$ Satoshi Kotani ${ }^{\mathrm{b}}$ Yoshiyuki Mishima $^{\mathrm{b}}$ Naoki Oshima ${ }^{\mathrm{b}}$ \\ Yoshikazu Kinoshitab \\ anflammatory Bowel Disease Center, Shimane University Hospital, Izumo, Japan; \\ ${ }^{\mathrm{b}}$ Department of Internal Medicine II, Shimane University Faculty of Medicine, Izumo, Japan
}

\section{Keywords}

Ulcerative colitis · Irritable bowel syndrome-like symptoms · Clinical remission - Endoscopic remission · Fecal

calprotectin

\section{Abstract}

Ulcerative colitis (UC) patients in clinical remission often experience irritable bowel syndrome (IBS)-like symptoms. The prevalence rate of UC patients meeting the definition of IBS, such as shown by the Rome criteria, is significantly higher in those without ongoing clinical activity as compared to healthy controls. Several studies have investigated residual low-grade inflammation found in colonic mucosa of quiescent UC patients and its association with development of IBS-like symptoms. In these patients, residual colonic inflammation was evaluated using endoscopy and histology findings, as well as fecal calprotectin level and shown to not be simply associated with the presence of IBS-like symptoms in UC patients in clinical remission. However, these results are limited by the low number of related investigations conduct- ed. Additional appropriately designed studies are necessary to confirm the relationship of low-grade colonic inflammation with IBS-like symptoms associated with UC.

두 2018 S. Karger AG, Base

\section{Introduction}

Irritable bowel syndrome (IBS), a functional disorder of the intestines, is characterized by abdominal pain and discomfort, along with alterations of bowel habits [1-5]. On the contrary, ulcerative colitis (UC), a major form of inflammatory bowel disease (IBD), is a chronic immuneand inflammation-mediated intestinal disorder characterized by clinical symptoms, including bloody stool, diarrhea, and fever. Organic intestinal lesions are not usually found in IBS patients, thus the IBS disease entity is recognized to be fundamentally different from IBD. However, recent studies have revealed that etiological factors, such as genetic background, history of infectious gastroenteritis, impaired gut barrier function, and psychological stress,

\section{KARGER}

(c) 2018 S. Karger AG, Basel

E-Mail karger@karger.com

www.karger.com/dig
Shunji Ishihara, $\mathrm{MD}, \mathrm{PhD}$

Department of Internal Medicine II, Inflammatory Bowel Disease Center Shimane University Hospital, Shimane University Faculty of Medicine 89-1, Enya-cho, Izumo, Shimane (Japan)

E-Mail si360405@med.shimane-u.ac.jp 
overlap between IBS and IBD [6-14]. Moreover, overlaps have also been observed between these diseases with regard to clinical symptoms [15]. Notably, IBS-like symptoms are often found in UC patients who have no evidence of the ongoing clinical disease activity $[6,8,16]$. Numerous studies have demonstrated possible mechanisms related to the development of IBS-like symptoms in quiescent UC patients [14-18]. In this review article, we focus on the degree of residual low-grade colonic inflammation in UC patients in clinical remission who were evaluated by endoscopy and histological findings, as well as fecal calprotectin (FC) level and discuss their association with the development of IBS-like symptoms.

\section{Prevalence of IBS in General Population}

A number of epidemiological studies have reported the prevalence of IBS in a variety of populations in various countries $[4,14,19,20]$. In an evaluation presented by Manning, prevalence based on Rome I or Rome II criteria ranged from 2.3 to $22 \%$ [21-24]. Furthermore, we recently reported that the prevalence of IBS in subjects who underwent general medical check-ups was $4.8 \%$ (Rome III criteria) [25]. On the contrary, a Japanese study conducted by Miwa [26] revealed that the prevalence of IBS was $13.1 \%$ (Rome III criteria). Although such heterogeneity may be dependent on the enrolled population, as well as sample size and the criteria used for diagnosis, the prevalence of IBS in the general population based on numerous previous studies is estimated to be approximately $10 \%$.

\section{Prevalence of IBS-Like Symptoms in UC Patients in Remission}

Successful treatment of UC patients with anti-inflammatory and immunomodulatory drugs leads to the induction of remission. However, even after remission has been induced, as assessed by validated clinical scores, some patients have frequent abdominal symptoms, such as pain and discomfort with altered bowel habits, which are widely recognized as "IBS-like symptoms."

Several previous studies enrolled patients without ongoing disease activity (clinical remission) and investigated the prevalence of symptoms meeting the criteria for IBS. Halpin and Ford [27] presented results of a systematic review and meta-analysis regarding the prevalence of IBS-like symptoms in UC patients in remission. They ex- amined 3,045 articles, and analyzed data obtained from 6 cross-sectional and 4 case-control studies selected from those that identified and reported IBS-like symptoms in examined patients, and reported a pooled prevalence of $31.0 \%$, which was significantly higher than that of the control cases in those studies (7.5\%). However, the remission criteria used in those studies varied, as some focused only on clinical symptoms as remission criteria [28-33], while others defined remission in their UC patients by evaluating both clinical and endoscopic findings [34-36]. Since residual colonic inflammation is often found in UC patients with clinical evidence of remission, it is possible that achievement of endoscopic remission (mucosal healing; $\mathrm{MH}$ ) in addition to the absence of ongoing clinical symptoms may reduce the development of IBS-like symptoms. Previous studies have reported that the prevalence of IBS-like symptoms is associated with the degree of $\mathrm{MH}$ assessed by endoscopic and histological examination findings, and FC level.

\section{Endoscopic Findings}

Isgar et al. [34] and Simrén et al. [35] included endoscopic findings in their criteria for determining remission of UC, though these definitions were not sufficiently validated. We found several studies including our own that discussed endoscopic findings in association with IBSlike symptoms in UC patients (Table 1). In these studies, Rome II or III criteria were used for the diagnosis of IBSlike symptoms, while endoscopic remission was defined by Mayo (MES $\leq 1$ ) or Matts (Matts grade $\leq 2$ ) endoscopic score. Ansari et al. [36] used MES $\leq 1$ to define endoscopic remission and found that the prevalence of IBSlike symptoms in such patients was $46 \%$, which was relatively higher as compared to previous studies of UC patients in clinical remission. We previously investigated the influence of endoscopic remission (Matts grade $\leq 2$ ) on prevalence of IBS-like symptoms in 172 UC patients in clinical remission (clinical activity index, CAI <4) [25]. However, the difference between clinical and endoscopic remission was not significant (26.7 vs. $25.6 \%)$. Furthermore, a more recent study revealed that the prevalence of IBS-like symptoms in UC patients in endoscopic remission (MES $\leq 1$ ) was $26.6 \%$, which was similar to that in previous studies of such patients [37].

Although Matts grade $\leq 2$ and MES $\leq 1$ are widely recognized for defining endoscopic remission, mild mucosal activity remains in the colonic mucosa of patients diagnosed as Matts grade 2 or MES 1 . In this regard, the prev- 
Table 1. Prevalence of IBS-like symptoms in UC patients in endoscopic remission

\begin{tabular}{llllll}
\hline Author (ref.) & Country & Criteria ${ }^{\#}$ & Criteria ${ }^{\dagger}$ & $\begin{array}{l}\text { Endoscopic } \\
\text { remission }\end{array}$ & $\begin{array}{l}\text { IBS-like } \\
\text { symptoms, } \\
(\%)\end{array}$ \\
\hline Ansari et al. [36] & Iran & Rome II & MES* $\leq 1^{*}$ & 50 & $23(46.0)$ \\
Fukuba et al. [25] & Japan & Rome III & Matts grade $\leq 2$ & 39 & $10(25.6)$ \\
& & & Matts grade $=1$ & 13 & $2(15.4)$ \\
Jonefjäll et al. [38] & Sweden & Rome III & MES $\leq 1^{* *}$ & 132 & $24(18.2)$ \\
Henriksen et al. [37] & Norway & Rome III & MES $\leq 1$ & 165 & $44(26.6)$ \\
& & & MES =0 & 118 & $30(27.1)$ \\
\hline
\end{tabular}

\# Criteria for diagnosis of IBS-like symptoms.

† Criteria for diagnosis of endoscopic remission.

$\$$ Number of patients in endoscopic remission.

** Remission criteria included fecal calprotectin $<200(\mu \mathrm{g} / \mathrm{g})$.

MES, mayo endoscopic subscore.

Table 2. Prevalence of IBS-like symptoms in association with fecal calprotectin levels

\begin{tabular}{|c|c|c|c|c|c|c|}
\hline \multirow[t]{2}{*}{ Author (ref.) } & \multirow[t]{2}{*}{ Country } & \multirow[t]{2}{*}{ UC patients* } & \multirow[t]{2}{*}{ Criteria** } & \multicolumn{2}{|c|}{ Fecal calprotectin $(\mu \mathrm{g} / \mathrm{g})$} & \multirow[t]{2}{*}{$p$ value } \\
\hline & & & & $\begin{array}{l}\text { IBS-positive } \\
\left(\mathrm{N}^{\mathbb{T}}\right)\end{array}$ & $\begin{array}{l}\text { IBS-negative } \\
\left(\mathrm{N}^{\mathbb{T}}\right)\end{array}$ & \\
\hline Keohane et al. [31] & Ireland & $n=44$ & Rome II & $591.1^{\#}(17)$ & $229.8^{\#}(27)$ & $<0.01$ \\
\hline Jelsness-Jørgense et al. [46] & Norway & $n=61$ & Rome III & $347.7^{\#}(15)$ & $189.3^{\#}(46)$ & ns \\
\hline Jonefjäll et al. [38] & Sweden & $n=132$ & Rome III & $18^{\$}(24)$ & $31^{\$}(108)$ & ns \\
\hline Hoekman et al. [47] & Netherland & $n=74$ & Rome III & $51^{\$}(33)$ & $77^{\$}(41)$ & ns \\
\hline Henriksen et al. [37] & Norway & $n=260$ & Rome III & $297^{\#}(71)$ & $197^{\#}(189)$ & ns \\
\hline
\end{tabular}

* Number of UC patients in clinical remission.

** Criteria for diagnosis of IBS-like symptoms.

I Number of patients with or without IBS-like symptoms.

\# Mean.

\$ Median.

alence of IBS-like symptoms may be decreased in patients with complete endoscopic remission, defined as Matts grade 1 and MES 0 [38]. In our previous study, when endoscopic remission was strictly defined as Matts grade 1, the prevalence of IBS-like symptoms decreased from 25.6 to $15.4 \%$ (Table 1) [25]. In contrast, a more recent study did not find a difference in regard to the prevalence of IBS-like symptoms between patients classified as MES 0 (25.4\%) and MES $\leq 1$ (26.6\%; Table 1) [37]. Therefore, it is unclear whether endoscopic evidence of remission is directly associated with the prevalence of IBS-like symptoms in UC patients in clinical remission. In fact, the number of studies of this issue is still quite limited and further investigations are necessary.

\section{Fecal Calprotectin Level}

Calprotectin is a calcium- and zinc-binding protein that is released mainly by neutrophils. Since infiltration of neutrophils during intestinal inflammation results in the release of calprotectin in stools, termed FC, its level is well correlated to mucosal activity in UC patients [3943]. In particular, FC level is considered to be an effective surrogate marker for evaluating mucosal healing in UC patients in clinical remission $[44,45]$.

Several groups have investigated the correlation between the prevalence of IBS-like symptoms and FC level in UC patients in clinical remission (Table 2). In a previous study reported by Keohane et al. [31], IBS-like symp- 
toms were detected in $38.6 \%$ of UC patients in remission (Rome II criteria) and were significantly associated with an increased level of FC. In a recent study reported by Jonefjäll et al. [38], who defined remission criteria based on endoscopic findings (MES $\leq 1)$ and FC level $(<200$ $\mu \mathrm{g} / \mathrm{g}$ ), the prevalence of IBS-like symptoms was relatively low (18.2\%) (Table 1). This latter finding suggests that a lower level of FC, in addition to endoscopic remission, may be associated with a reduced rate for the prevalence of IBS-like symptoms.

On the contrary, recently published studies that used Rome III criteria did not find a correlation between FC level and prevalence of IBS-like symptoms, though average or mean FC levels varied among them (Table 2) $[31,37,38,46,47]$. In our recent study, we also did not find a significant increase in the level of FC in UC patients with IBS-like symptoms in clinical remission (data not shown). Thus far, the results of studies related to this issue remain controversial, and possibly dependent on the study population and sample size, as well as remission criteria used for defining UC and IBS-like symptoms.

\section{Histological Findings}

Histological changes such as infiltration of various inflammatory cells without endoscopic evidence of inflammation have been found in certain populations of IBS patients. These findings have been primarily observed in patients with post-infectious IBS (PI-IBS), which is defined as a type of IBS that develops in previously asymptomatic individuals following an episode of acute gastroenteritis caused by bacterial or viral infection [4-7]. PIIBS is found in approximately $10-20 \%$ of patients diagnosed with IBS $[4,14,48]$. Previous studies of affected patients have reported a variety of immune cells, including $\mathrm{T}$ cells $\left(\mathrm{CD}^{+}, \mathrm{CD}^{+}, \mathrm{CD}^{+}\right.$cells), macrophages, $B$ cells, and mast cells, infiltrating the mucosa of the small and large intestines without endoscopic inflammation. In addition, increased levels of interleukin- $1 \beta$ and interferon- $\gamma$ have been found in rectal and colonic biopsy tissues in patients with PI-IBS [4, 14, 49-52]. Taken together, these findings suggest that histological evidence of intestinal inflammation in the absence of endoscopic activity may have a relationship with the pathogenesis of IBS.

On the contrary, residual low-grade histological inflammation is often found in the colonic mucosa of UC patients even after they show clinical and endoscopic re- mission [53], which might be associated with the development of IBS-like symptoms. Recently, Henriksen et al. [37] investigated the influence of histological inflammation on the prevalence of IBS-like symptoms in UC patients with endoscopic evidence of remission and lower FC levels. They did not find reduced frequency of IBS-like symptoms in these cases, even when histological inflammation was not revealed in colonic biopsy findings. The study was the first to report the influence of histological inflammation on IBS-like symptoms in UC patients in remission. In patients with PI-IBS, various factors related to systemic immune activation, in addition to histological inflammation, have been reported. In this regard, the pathogenesis of IBS symptoms in PI-IBS patient may differ from that in UC patients in remission, though lowgrade histological inflammation is observed in association with both disease entities.

\section{Relapse of UC with or without IBS-Like Symptoms}

In a recent investigation, we reviewed the records of UC patients in clinical remission who had been enrolled in our previous study to determine the period without relapse in association with IBS-like symptoms. In the clinical remission group with IBS-like symptoms, the mean relapse-free period was shorter as compared to that of patients in the group without such symptoms, suggesting that the presence of IBS-like symptoms is predictive of UC relapse [54]. However, endoscopic activity (Matts grade) was significantly higher in the group of patients with IBS-like symptoms. Therefore, we speculate that residual inflammation in colonic mucosa might have an influence on UC relapse. Nevertheless, this is the only study presented that investigated this issue and further investigations to confirm the influence of IBS-like symptoms on relapse of UC are needed.

\section{Conclusion}

Our findings indicate that the degree of residual lowgrade colonic inflammation, as evaluated by endoscopy and histology findings, as well as FC level, is not correlated with the prevalence rate of IBS-like symptoms in all cases. Although IBS-like symptoms in certain patients may be predominantly affected by low-grade colonic inflammation, such a population has not been clearly shown, possibly because of the limited number of appropriate studies. On the contrary, apart from colonic in- 
flammation, the pathogenesis of IBS has been reported to be associated with a variety of factors, including genetics, visceral hypersensitivity, increased gut permeability, microbiota dysbiosis, immune activation, and abnormal serotonin metabolism. Overlaps between colonic inflammation and those factors might have an influence on the presence of IBS-like symptoms in quiescent UC patients. Additional studies are necessary to more fully understand the pathogenesis of IBS-like symptoms in UC patients in remission, ultimately leading to the development of new therapeutic options.

\section{Disclosure Statement}

The authors have no financial or other conflicts of interest to declare in relation to the contents of this article.

\section{References}

1 Thompson WG, Heaton KW, Smyth GT, Smyth C: Irritable bowel syndrome in general practice: prevalence, characteristics, and referral. Gut 2000;46:78-82.

2 Cremonini F, Talley NJ: Irritable bowel syndrome: epidemiology, natural history, health care seeking and emerging risk factors. Gastroenterol Clin North Am 2005;34:189-204.

3 Talley NJ: Irritable bowel syndrome. Intern Med J 2006;36:724-728.

4 Spiller R, Aziz Q, Creed F, Emmanuel A, Houghton L, Hungin P, Jones R, Kumar D, Rubin G, Trudgill N, Whorwell P; Clinical Services Committee of The British Society of Gastroenterology: Guidelines on the irritable bowel syndrome: mechanisms and practical management. Gut 2007;56:1770-1798.

5 Spiller R: Clinical update: irritable bowel syndrome. Lancet 2007;369:1586-1588.

6 Ohman L, Simrén M: Pathogenesis of IBS: role of inflammation, immunity and neuroimmune interactions. Nat Rev Gastroenterol Hepatol 2010;7:163-173.

7 El-Salhy M: Irritable bowel syndrome: diagnosis and pathogenesis. World J Gastroenterol 2012;18:5151-5163.

8 Spiller R, Lam C: The shifting interface between IBS and IBD. Curr Opin Pharmacol 2011;116:586-592.

9 Elsenbruch S: Abdominal pain in Irritable Bowel Syndrome: a review of putative psychological, neural and neuro-immune mechanisms. Brain Behav Immun 2011;25:386-394.

10 Bashashati M, Rezaei N, Andrews CN, Chen CQ, Daryani NE, Sharkey KA, Storr MA: Cytokines and irritable bowel syndrome: where do we stand? Cytokine 2012;572:201-209.

11 Burgmann T, Clara I, Graff L, Walker J, Lix L, Rawsthorne P, McPhail C, Rogala L, Miller N, Bernstein CN: The Manitoba Inflammatory Bowel Disease Cohort Study: prolonged symptoms before diagnosis - how much is irritable bowel syndrome? Clin Gastroenterol Hepatol 2006;4:614-620.

12 Porter CK, Tribble DR, Aliaga PA, Halvorson HA, Riddle MS: Infectious gastroenteritis and risk of developing inflammatory bowel disease. Gastroenterology 2008;135:781-786.

13 Murakami T, Kamada K, Mizushima K, Higashimura $\mathrm{Y}$, Katada K, Uchiyama K, Handa O, Takagi T, Naito Y, Itoh Y: Changes in in- testinal motility and gut microbiota composition in a rat stress model. Digestion 2017;95: 55-60.

14 Ishihara S, Aziz M, Oshima N, Mishima Y, Imaoka H, Moriyama I, Kinoshita Y: Irritable bowel syndrome and inflammatory bowel disease: Infectious gastroenteritis-related disorders? Clin J Gastroenterol 2009;2:9-16.

15 Quigley EM: Overlapping irritable bowel syndrome and inflammatory bowel disease: less to this than meets the eye? Therap Adv Gastroenterol 2016;9:199-212.

16 Teruel C, Garrido E, Mesonero F: Diagnosis and management of functional symptoms in inflammatory bowel disease in remission. World J Gastrointest Pharmacol Ther 2016;7: 78-90.

17 Spiller R: Irritable bowel syndrome: new insights into symptom mechanisms and advances in treatment. F1000Res 2016;5:780.

18 Spiller R, Major G: IBS and IBD - separate entities or on a spectrum? Nat Rev Gastroenterol Hepatol 2016;13:613-621.

19 Bommelaer G, Poynard T, Le Pen C, Gaudin AF, Maurel F, Priol G, Amouretti M, Frexinos J, Ruszniewski P, El Hasnaoui A: Prevalence of irritable bowel syndrome (IBS) and variability of diagnostic criteria. Gastroenterol Clin Biol 2004:28:554-561.

20 Thompson WG, Irvine EJ, Pare P, Ferrazzi S, Rance L: Functional gastrointestinal disorders in Canada: first population-based survey using Rome II criteria with suggestions for improving the questionnaire. Dig Dis Sci 2002;47:225-235.

21 Wilson S, Roberts L, Roalfe A, Bridge P, Singh S: Prevalence of irritable bowel syndrome: a community survey. Br J Gen Pract. 2004;54: 495-502.

22 Hillila MT, Farkkila MA: Prevalence of irritable bowel syndrome according to different diagnostic criteria in a non-selected adult population. Aliment Pharmacol Ther 2004; 20:339-345

23 Gwee KA, Wee S, Wong ML, Png DJ: The prevalence, symptom characteristics, and impact of irritable bowel syndrome in an asian urban community. Am J Gastroenterol. 2004; 99:924-931

24 Rajendra S, Alahuddin S: Prevalence of irritable bowel syndrome in a multi-ethnic Asian population. Aliment Pharmacol Ther 2004; 19:704-706.

25 Fukuba N, Ishihara S, Tada Y, Oshima N, Moriyama I, Yuki T, Kawashima K, Kushiyama Y, Fujishiro H, Kinoshita Y: Prevalence of irritable bowel syndrome-like symptoms in ulcerative colitis patients with clinical and endoscopic evidence of remission: prospective multicenter study. Scand J Gastroenterol 2014;49:674-680.

26 Miwa H: Prevalence of irritable bowel syndrome in Japan: Internet survey using Rome III criteria. Patient Prefer Adherence 2008;2: 143-147.

27 Halpin SJ, Ford AC: Prevalence of symptoms meeting criteria for irritable bowel syndrome in inflammatory bowel disease: systematic review and meta-analysis. Am J Gastroenterol 2012;107:1474-1482.

28 Zaman MS, Robson KM, Lembo AJ: Overlap of irritable bowel syndrome (IBS) symptoms in patients with inflammatory bowel disease (IBD). Am J Gastroenterol 2002;97(suppl):S284.

29 Minderhoud IM, Oldenburg B, Wismeijer JA, van Berge Henegouwen GP, Smout AJ: IBSlike symptoms in patients with inflammatory bowel disease in remission; relationships with quality of life and coping behavior. Dig Dis Sci 2004;49:469-474.

30 Farrokhyar F, Marshall JK, Easterbrook B, Irvine EJ: Functional gastrointestinal disorders and mood disorders in patients with inactive inflammatory bowel disease: prevalence and impact on health. Inflamm Bowel Dis 2006; 12:38-46.

31 Keohane J, O'Mahony C, O'Mahony L, O'Mahony S, Quigley EM, Shanahan F: Irritable bowel Syndrome-Type symptoms in patients with inflammatory bowel disease: a real association or reflection of occult inflammation? Am J Gastroenterol 2010;105:17891794.

32 Barratt SM, Leeds JS, Robinson K, Shah PJ Lobo AJ, McAlindon ME, Sanders DS: Reflux and irritable bowel syndrome are negative predictors of quality of life in coeliac disease and inflammatory bowel disease. Eur J Gastroenterol Hepatol 2011;23:159-165.

33 Berrill J, Ludlow H, Green J: Functional symptoms in inflammatory bowel disease. J Crohns Colitis 2012;6(suppl 1):S66. 
34 Isgar B, Harman M, Kaye M, Whorwell P: Symptoms of irritable bowel syndrome in ulcerative colitis in remission. Gut 1983;24: 190-192.

35 Simrén M, Axelsson J, Gillberg R, Abrahamsson $\mathrm{H}$, Svedlund J, Björnsson ES: Quality of life in inflammatory bowel disease in remission: the impact of IBS-like symptoms and associated psychological factors. Am J Gastroenterol 2002;97:389-396.

36 Ansari R, Attari F, Razjouyan H, Etemadi A, Amjadi H, Merat S, Malekzadeh R: Ulcerative colitis and irritable bowel syndrome: relationships with quality of life. Eur J Gastroenterol Hepatol 2008;20:46-50.

37 Henriksen M, Høivik ML, Jelsness-Jørgensen LP, Moum B; IBSEN Study Group: Irritable bowel-like symptoms in ulcerative colitis are as common in patients in deep remission as in inflammation: results from a populationbased study [the IBSEN Study]. J Crohns Colitis 2018;12:389-393.

38 Jonefjäll B, Öhman L, Simrén M, Strid H: IBSlike symptoms in patients with ulcerative colitis in deep remission are associated with increased levels of serum cytokines and poor psychological well-being. Inflamm Bowel Dis 2016;22:2630-2640.

39 Langhorst J, Elsenbruch S, Koelzer J, Rueffer A, Michalsen A, Dobos GJ: Noninvasive markers in the assessment of intestinal inflammation in inflammatory bowel diseases: performance of fecal lactoferrin, calprotectin, and PMN-elastase, CRP, and clinical indices. Am J Gastroenterol 2008;103:162-169.

40 Schoepfer AM, Beglinger C, Straumann A, Trummler M, Renzulli P, Seibold F: Ulcerative colitis: correlation of the Rachmilewitz endoscopic activity index with fecal calprotectin, clinical activity, C-reactive protein, and blood leukocytes. Inflamm Bowel Dis 2009;15:1851-1858.

41 D'Haens G, Ferrante M, Vermeire S, Baert F, Noman M, Moortgat L, Geens P, Iwens D,
Aerden I, Van Assche G, Van Olmen G, Rutgeerts P: Fecal calprotectin is a surrogate marker for endoscopic lesions in inflammatory bowel disease. Inflamm Bowel Dis 2012; 18:2218-24.

42 Kawashima K, Ishihara S, Yuki T, Fukuba N, Oshima N, Kazumori H, Sonoyama H, Yamashita N, Tada Y, Kusunoki R, Oka A, Mishima Y, Moriyama I, Kinoshita Y: Fecal calprotectin level correlated with both endoscopic severity and disease extent in ulcerative colitis. BMC Gastroenterol 2016;16:47.

43 Mine S, Takeshima F, Akazawa Y, Matsushima K, Minami H, Yamaguchi N, Ohnita K, Isomoto $\mathrm{H}$, Nakao $\mathrm{K}$ : Correlation of fecal markers with magnifying endoscopic stratification in patients with ulcerative colitis who are in clinical remission. Digestion 2018;97: 82-89.

44 D’Angelo F, Felley C, Frossard JL: Calprotectin in daily practice: where do we stand in 2017? Digestion 2017;95:293-301.

45 Daperno M, Castiglione F, de Ridder L, Dotan I, Färkkilä M, Florholmen J, Fraser G, Fries W, Hebuterne X, Lakatos PL, Panes J, Rimola J, Louis E; Scientific Committee of the European Crohn's and Colitis Organization: Results of the 2nd part Scientific Workshop of the ECCO. II: measures and markers of prediction to achieve, detect, and monitor intestinal healing in inflammatory bowel disease. J Crohns Colitis 2011;5:484-498.

46 Jelsness-Jørgensen LP, Bernklev T, Moum B: Fatigue and disease-related worries among inflammatory bowel disease patients in remission; is it a reflection of coexisting IBS-like symptoms? A short report. J Psychosom Res 2012;73:469-472.

47 Hoekman DR, Zeevenhooven J, D'Haens GR, Benninga MA: The prevalence of irritable bowel syndrome-type symptoms in inflammatory bowel disease patients in remission. Eur J Gastroenterol Hepatol 2017;29:10861090.
48 Thabane M, Kottachchi DT, Marshall JK: Systematic review and meta-analysis: the incidence and prognosis of post-infectious irritable bowel syndrome. Aliment Pharmacol Ther 2007;26:535-544.

49 Spiller RC, Jenkins D, Thornley JP, Hebden JM, Wright T, Skinner M, Neal KR: Increased rectal mucosal enteroendocrine cells, T lymphocytes, and increased gut permeability following acute Campylobacter enteritis and in post-dysenteric irritable bowel syndrome. Gut 2000;47:804-811.

50 Dunlop SP, Jenkins D, Neal KR, Spiller RC: Relative importance of enterochromaffin cell hyperplasia, anxiety, and depression in postinfectious IBS. Gastroenterology 2003; 125:1651-1659.

51 Gwee KA, Collins SM, Read NW, Rajnakova A, Deng Y, Graham JC, McKendrick MW, Moochhala SM: Increased rectal mucosal expression of interleukin lbeta in recently acquired post-infectious irritable bowel syndrome. Gut 2003;52:523-526.

52 Ishihara S, Tada Y, Fukuba N, Oka A, Kusunoki R, Mishima Y, Oshima N, Moriyama I, Yuki T, Kawashima K, Kinoshita Y: Pathogenesis of irritable bowel syndrome review regarding associated infection and immune activation. Digestion 2013;87:204211.

53 Guardiola J, Lobatón T, Rodríguez-Alonso L, Ruiz-Cerulla A, Arajol C, Loayza C, Sanjuan X, Sánchez E, Rodríguez-Moranta F: Fecal level of calprotectin identifies histologic inflammation in patients with ulcerative colitis in clinical and endoscopic remission. Clin Gastroenterol Hepatol 2014;12:18651870.

54 Fukuba N, Ishihara S, Kawashima K, Mishima Y, Oshima N, Kinoshita Y: Irritable bowel syndrome-like symptoms associated with endoscopic activity predict ulcerative colitis relapse in patients with clinical remission. Intest Res 2017;15:543-545. 